\title{
A HANDHELD, FREE ROAMING, DATA DISPLAY FOR DIII-D DIAGNOSTIC DATA
}

\author{
J.D. BROESCH, J.C. PHILLIPS, P.I. PETERSEN, \\ and M.J. HANSINK
}

This is a preprint of a paper to be presented at the 11th IEEE/NPSS

Real Time Conference, June 14-18, 1999, Santa Fe, New Mexico and to be published in Transactions on Nuclear Science.

\author{
Work supported by \\ the U.S. Department of Energy \\ under Contract No. DE-AC03-99ER54463
}

GA PROJECT 30033

JULY 1999 


\section{DISCLAIMER}

This report was prepared as an account of work sponsored by an agency of the United States Government. Neither the United States Government nor any agency thereof, nor any of their employees, make any warranty, express or implied, or assumes any legal liability or responsibility for the accuracy, completeness, or usefuiness of any information, apparatus, product, or process disclosed, or represents that its use would not infringe privately owned rights. Reference herein to any specific commercial product, process, or service by trade name, trademark, manufacturer, or otherwise does not necessarily constitute or imply its endorsement, recommendation, or favoring by the United States Government or any agency thereof. The views and opinions of authors expressed herein do not necessarily state or reflect those of the United States Government or any agency thereof. 


\section{DISCLAIMER}

Portions of this document may be illegible in electronic image products. Images are produced from the best available original document. 


\title{
A Handheld, Free Roaming, Data Display for DIII-D Diagnostic Data
}

\author{
J.D. Broesch, J.C. Phillips, P.I. Petersen, and M.J. Hansink \\ General Atomics, P.O. Box 85608, San Diego, California 92186-5608
}

\begin{abstract}
Standard handheld test instruments such as voltmeters and portable oscilloscopes are useful for making basic measurements necessary for the operation and maintenance of large experiments such as the DIII-D magnetic fusion research facility. Some critical diagnostic information, however, is available only on system computers. Often this diagnostic information is located in computer databases and requires synthesis via computational algorithms to be of practical use to the technician. Unfortunately, this means the data is typically only available via computer screens located at fixed locations. One common way to provide mobile information is to have one operator sit at a console and read the data to the mobile technician via radio. This is inefficient in as much as it requires two pople. Even more importantly the operator-to-technician voice link introduces significant delays and errors that may hinder response times. To address these concerns of personnel utilization and efficiency, we have developed a remote display based on an rf-data link that can be carried with a technician as he moves about the facility. This display can provide the technician with any information needed from the stationary database. This paper will discuss the overall architecture as well as the individual modules for the mobile data display. Lessons learned, as well as techniques for improving the usefulness of such systems, will be presented.
\end{abstract}

\section{INTRODUCTION}

The need to remotely access diagnostic data for operations and maintenance activities has led to the requirement to develop a system that could display any selected piece of data in the DIII-D database on a handheld display. This new device would then become as useful and convenient as the conventional diagnostics tools normally used by machine operators and technicians. The prototype device has been received with sufficient enthusiasm that anticipated applications for the system have been expanded to include a wide range of experimental and engineering data.

\section{DERIVED DESIGN REQUIREMENTS}

The basic requirement for a handheld display naturally led to a series of derived requirements for the complete remote display system. The handheld device must be approximately the size of a standard instrument such as a VOM (Volt Ohm Meter). In order to provide sufficient mobility for the operator, the handheld unit must have a range greater than $1000 \mathrm{ft}$ from the base unit. This range must be achieved over constantly varying propagation paths and in the presence of a wide number of noise sources commonly found in large tokamak experiments. Due to the mobile nature of the system, it must be relatively immune to signal blocking from pipes, large metal assemblies, power wiring, etc. The need to operate from batteries dictates that all components have low power consumption.

The data communication paths are particularly interesting due to the fact that the system employs conventional data formats. Practicality dictated a conventional TCP/IP interface between the rf link and the control computer, for example. Additionally, cost and other practical requirements dictated that the system should not require any special FCC approvals.

Overall, the system was somewhat cost sensitive. Due to the fact that relatively few units were to be put in to operation, a COTS (commercial off the shelf) approach was desired.

\section{DESIGN SOLUTION}

A number of approaches to meet the requirements were evaluated. First was a complete COTS solution. There are a number of rf-data link systems available. However all identified systems were deemed unsuitable for this particular application. Most of these systems were designed for inventory control, product tracking, etc. These systems could not be easily adapted to this application. Other systems could be adapted, but were too expensive. Typically these systems required custom antennas and expensive base transceivers.

This led us to a semi-custom solution. The high noise immunity requirement, coupled with the need to adapt to different - and changing - signal propagation paths, dictated a solution based on spread spectrum technology. Fortunately, the FCC (Federal Communications Commission) has opened a $900 \mathrm{MHz}$ band for just such applications. The band is called the ISM (Instrumentation, Scientific, and Medical) and is authorized under FCC Part 15 for data transmission using spread spectrum techniques. In addition to the simple data communications, the ability to communicate with various nodes was desired. This dictated that the rf portion of the system support a built-in networking capability (Fig. 1).

These requirements led to the selection of the Hummingbird transceiver by Xetron [1] for the rf link portion of remote data display. Since the baseband interface to the Xetron is RS-232, this led to a derived requirement for a TCP/IP to RS-232 interface. The MSS-1 from Lantronix [2] was selected to meet this derived requirement (Fig. 2). Battery operation required an efficient DC-DC power converter. A new, highly efficient DC-DC converter chip, the MAX1703 from Maxim [3] was chosen as the core of the power supply circuit.

\footnotetext{
*Work supported by U.S. Department of Energy under Contract No. DE-AC03-99ER54463.
} 


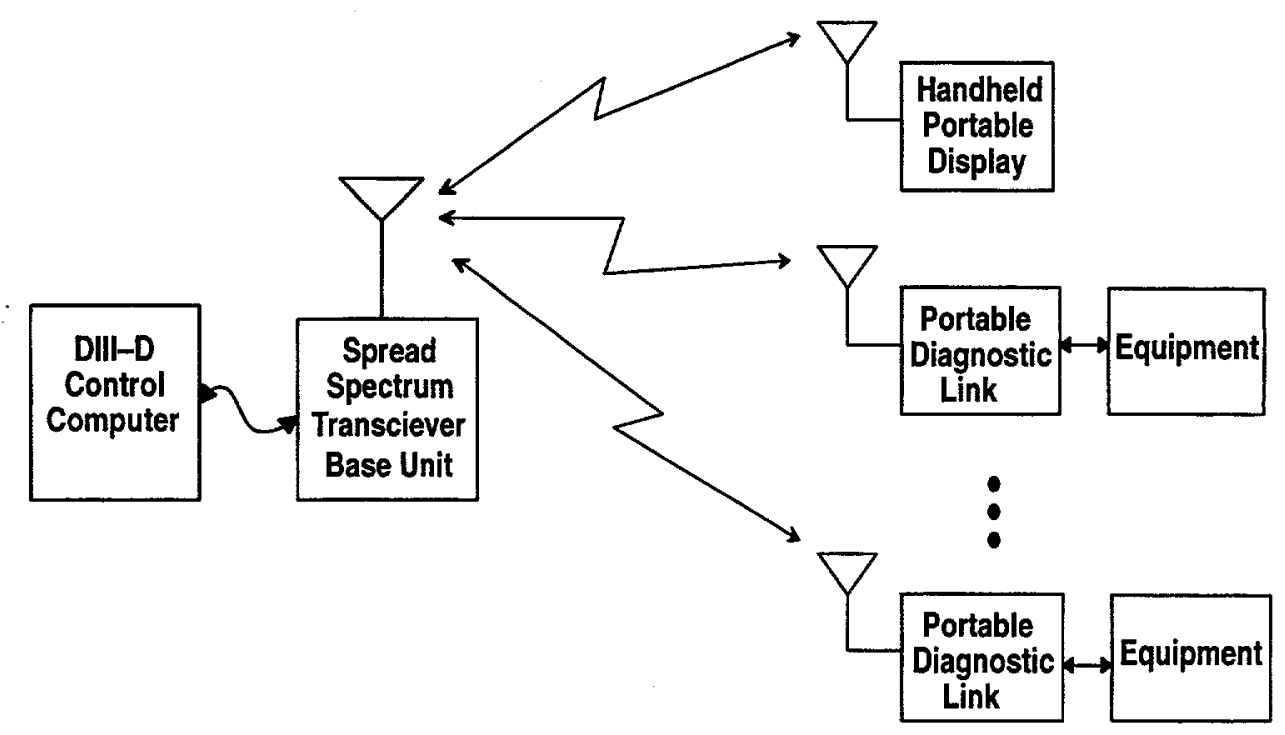

Fig. 1. The base unit side of the rf-datalink.

Finally, some means for displaying the data was needed. The BPP-420 serial LCD Display from Scott Edwards Electronics [4] provides a compact, easily interfaced solution.

The block diagram of the remote unit is shown in Fig. 3.

To the control computer the remote display unit appears as a TCP/IP socket.

\section{SYSTEM USE}

The remote handheld display was initially put into use during the pump down of the DIII-D vacuum vessel to monitor vessel pressure (VG-1). The system worked well and was enthusiastically received. This has led to requests to expand its usability in its current role, and to request for new applications of the system such as monitoring parameters for glow discharge cleaning (GDC). Other anticipated applications include monitoring high voltage signals across isolation barriers and the monitoring of diagnostic signals from areas that are not easily reached during operations.

As configured, the remote data display can display 8 parameters. The display is updated once a second. This rate is limited by the control computer; overall, the system is capable of transferring data at $19.2 \mathrm{~KB}$.
Operational testing lead to several improvements in the baseline design. One potential problem that only became apparent in the initial checkout of the system was the need to insure that the data being displayed is truly current. The Hummingbird provides an RSS (Received Signal Strength) indicator which can be used to indicate that two rf units are in communication. It is possible, however, for the network link between the control computer and the base unit to fault without it being obvious that data on the display is no longer being updated. This problem was addressed by having the control computer transmit the current time as well as the relevant data. Both monitoring of the RSS indication and noting that the time is in fact changing provides positive indication that the data is valid. This is a somewhat inelegant solution, however. As noted below, the next generation device will improve on this deficiency.

A second, minor, problem comes from the fact that some operations of the display, such as the backlight, are controlled via the RS-232 port. This means that the operator must control this function from the control computer, rather than from the hand held display.

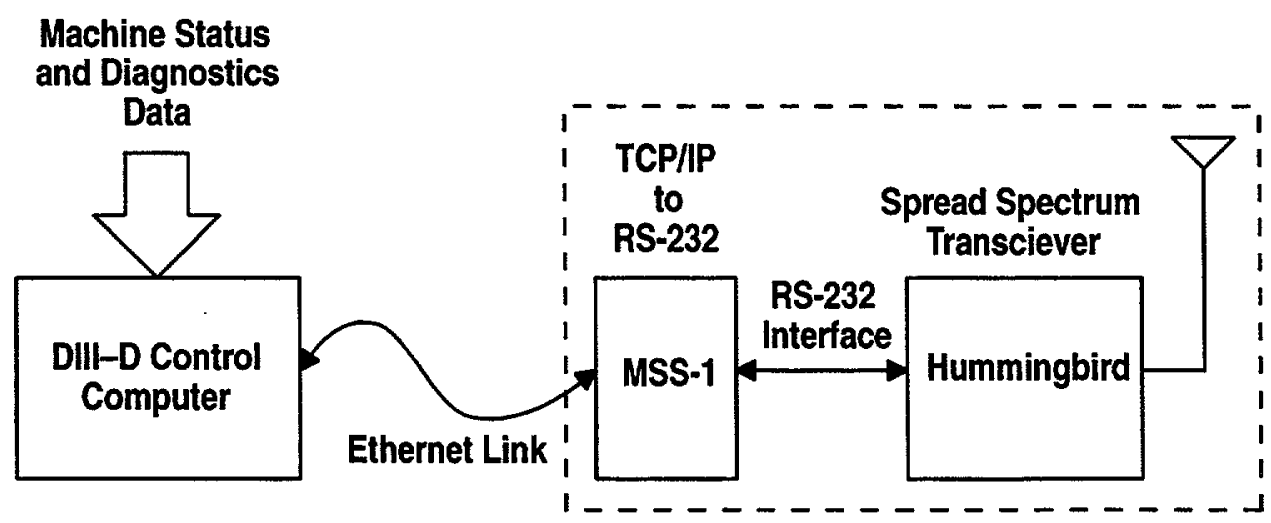

Fig. 2. An overview of the complete system. 


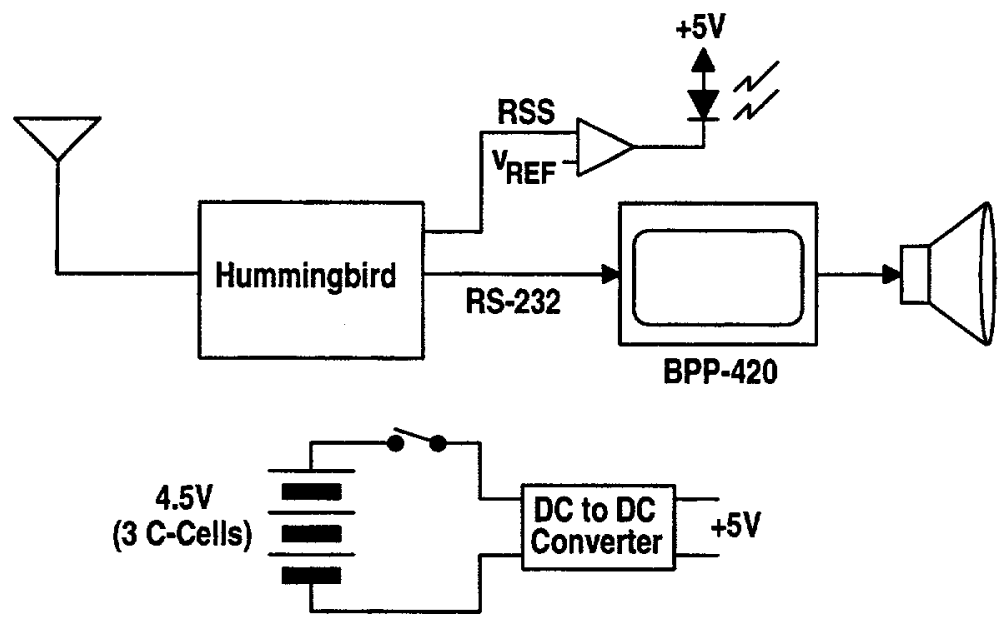

Fig. 3. Block diagram of the portable unit.

\section{IMPROVEMENTS}

The user requested enhancements are being addressed by adding a microcontroller to the handheld display. The micrcontroller will allow limited two-way communications. Additionally, it will allow the operator to control the display operation from the handheld unit. Most importantly, however, the microcontroller will monitor the data stream from the control computer. If the data stream is interrupted for any reason, the microcontroller will clear the display and then indicate that no valid data is available. Another feature that the microcontroller will implement is the ability to set an alarm range on the monitored parameter. If the value of the parameter moves out of range, the microcontroller will sound an audible signal. This feature will allow eyes-off use of the system. A block diagram of the next generation display is shown in Fig. 4. Further improvements include long-life, rechargeable battery power.

\section{CONCLUSION}

$\mathrm{RF}$ data networking is an increasingly attractive option for use on a variety of experiments. Low cost, efficient COTS components are used to implement these networks. As demonstrated, these rf networks can be easily interfaced with existing standard networks.

\section{REFERENCES}

[1] Xetron Corporation, 460 West Crescentville Rd., Cincinnati, Ohio 45246, Phone: (513) 881-3100.

[2] Lantronix, 15353 Barranca Pkwy, Irvine, CA 92618 U.S.A., Phone: (800) $422-7055$.

[3] Maxim Integrated Products, Inc., 120 San Gabriel Drive, Sunnyvale, CA 94086, Phone: (408) 737-7600.

[4] Scott Edwards Electronics Inc., 1939 S. Frontage Rd., Suite F., Sierra Vista, AZ 85635, Phone (520) 459-4802.

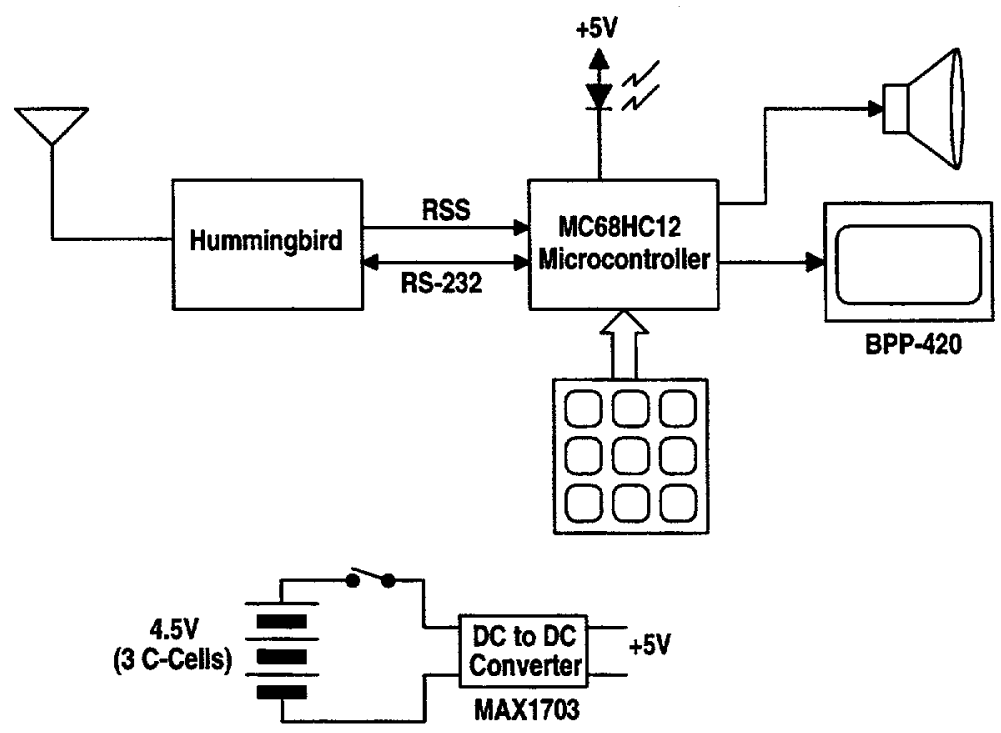

Fig. 4. Block diagram of the next generation display. 